\title{
DOCUMENTACION
}

\section{Doctorado en teología honoris causa en la Universidad Centroamericana José Simeón Cañas}

\subsection{Acta del Consejo Superior Universitario}

El Consejo Superior Universitario de la Universidad Centroamericana José Simeón Cañas considerando:

a) Que Monseñor Oscar Arnulfo Romero y Galdámez ha sido uno de los salvadorentos más notables en toda la historia del pais y una de las figuras más extraordinarias de America Latina y del mundo en los últimos años;

b) Que de ello dan testimonio muchas instituciones nacionales e internacionales que despues de su muerte llevan su nombre, así como numerosas distinciones públicas que se le concedieron en vida y después de muerto, algunas de las cuales son:

- el doctorado honoris causa que en 1978 le otorgó la Universidad de Georgetwon (Washington, Estados Unidos), en 1980 la Universidad Católica de Lovaina (Bélgica) y en 1981 la Universidad de El Salvador;

- la nominación para el Premio Nobel de la Paz que en 1979 propusieron más de cien parlamentarios británicos, secundados por numerosas personalidades e instituciones de todo el mundo;

- la concesión en 1980 del Premio de la Paz en Suecia;

c) Que Monseñor Romero y Galdámez cumplió eximiamente a través de su mision pastoral con la finalidad de la UCA de ser conciencia crítica y constructiva de la realidad salvadoreña desde la bptica de las mayorías populares; fue voz de los sin voz, defensa de los oprimidos y esperanza de los pobres, realizando así los objetivos de la UCA de servir universitariamente como voz de la verdad, defensa de la razon y esperanza de una sociedad más justa; d) Que Monseffor Romero y Galdamez fue y sigue siendo inspirador de una teología y un quehacer pastoral que busca la construcción del Reino de Dios mediante la opción preferencial por los pobres;

e) Que Monseñor Roinero y Galdámez acompañó a la UCA como pastor, intelectual y amigo, participó en actos públicos extracurriculares de esta Universidad y con frecuencia defendió públicamente en sus homilias dominicales a miembros de la comunidad universitaria, a la revista $E C A$ y a la $U C A$ como tal frente a las amenazas y ataques en su contra;

f) Que este Consejo considera oportuno revivir el espiritu de Monseftor Romero y Galdámez en la UCA para que dinamice su compromiso con la verdad y su búsqueda de la justicia en un clima de cooperación y diálogo;

g) Que frente a la creciente sumisión de nuestro pais, el vacio de liderazgo y la ausencia de ideales nacionales, es urgente presentar a las nuevas generaciones de salvadorenos una imagen como la de Monseffor Romero y Galdámez, modelo de servicio y de mando, de solidaridad y de independencia, de nacionalismo y de universalidad.

Por tanto, en virtud de sus atribuciones y con el voto unánime de sus miembros, acuerda otorgar el doctorado honoris causa en teologia a título posstumo a Monseffor Oscar Amulfo Romero y Galdámez.

San Salvador, marzo de 1985

\subsection{Título concedido a Mons. Oscar A. Romero}

La Universidad Centroamericana José Simeb́n Caîas conflere a

Monseñor Oscar Amulfo Romero y Galdámez el gredo de

Doctor en Teologia honoris causa
Monsefor debe ser considerado con toda justicia uno de los salvadoreftos más notables en la historia del pais ya que su accion ha transcendido las fronteras patrias para convertirse en figura ejemplar, reconocida mundialmente. 
Vino a servir y no a ser servido, dio la vida por aquellos a los que debía guardar y defender, y se convirtió así en ejemplo permanente de amor a los demás.

Fue la voz de los sin voz y, alzado sobre el clamor de su pueblo, por cuyos sectores más pobres habia optado preferencialmente, defendio en El Salvador la causa de la historia, de la liberación y de la paz.

Con su vida, su acción y su palabra se convirtio en fuente de sabiduría cristiana y en luz para desarrollar una teología académica rigurosa, que respondiese a las necesidades del pueblo de Dios en situaciones de pobreza, injusticia y conflicto social.

Su figura como hombre, como religioso, como intelectual y como persona comprometida con su pueblo constituye un modelo para todos aquellos que anhelan una sociedad más acogedora, justa y libre.

La Universidad Centroamericana José Simeón Cañas, al concederle este reconocimiento póstumo, no soblo se honca a sí misma, sino que se compromete a seguir ese mismo camino, que él más de una vez le animó a recorrer.

Dado en San Salvador, a los veintidos dias del mes de marzo del año mil novecientos ochenta y cinco, quinto aniversario de su muerte.

\section{Ignacio Ellacuría Reclor}

\section{Mario Cerna \\ Secretario General}

Segundo Montes Decano

\subsection{Palabras de Mons. Arturo Rivera Damas}

\section{Ilustrisimo Seffor Rector \\ Claustro de Profesores \\ Distinguidos Visitantes \\ Sefforas y Sentores}

En diciembre de 1979, me pidió Monseñor Romero que lo representara en Holanda, donde la Organización Ecuménica "Solidaridad," quería hacerle un homenaje. Como es natural, traté de excusarme, pues en esos casos, lo que pretenden los organizadores es contar con la presencia del homenajeado y no con la presencia de un delegado. Para evitar sorpresas a mi llegada, pedi que se consultara previamente la posible sustitución de Monseffor por mi persona y qué aceptación habria del sustituto, y sólo cuando la respuesta fue afirmativa nos hicimos al camino en compania de Monseñor Urioste.

El recorrido por varias ciudades de los Paises Bajos, fue impresionante: por el calor humano y la admiración que sentian por Monseñor Romero, por la importancia de las personas que pudimos contactar, incluso todos los Obispos, reunidos en Conferencia Episcopal, y por la variedad y calidad de los actos, al culminar de los cuales, en la Iglesia de San Agustin, de la ciudad de Uttrech, nos hicieron entrega de un cheque de $\$ 30.000 .00$ dolares; para que la radiodifusora YSAX, siguiera difundiendo el pensamiento y la palabra del Pastor.

A mi vuelta, la vispera de Navidad, le recomendé de todas veras que no faltara a esas invitaciones y homenajes porque resultaba dificil complacer debidamente a los que le deseaban ver y oír directamente y no por interpósita persona.

Cuando se acercaba el día en que la Universidad de Lovaina le iba a conceder el título de Doctor Honoris Causa, me pidió más de una vez que lo sustituyera.

Con la fuerza que venía de la reciente experiencia lo animé a que fuera personalmente. Me imagino que otros muchos lo animaron tambien a ir. Fue; y sabemos el eco que despertó su presencia y su palabra, en el aula magna de aquella Pontificia Universidad cargada de tradición y prestigio.

Cuando regresaba nos vimos en Panamá, donde yo par- ticipaba en un Encuentro de Doctrina Social de la Iglesia. Venía contento y me comento, entre otras cosas, que yo tenía razon en insistir en que él fuera personalmente.

Hoy Monseñor habita en la Casa del Padre, y en la mente y el corazon de muchos, especialmente de los que ansian pasar de condiciones menos humanas a condiciones más humanas.

Es la segunda vez, que lo represento en homenajes póstumos de carácter académico: en mayo de 1980, cuando la Universidad de El Salvador, en reconocimiento a sus méritos de Pastor y Maestro, le concedió la distinción de Doctor Honoris Causa y hoy, cuando la Universidad Centroamericana, José Simeón Cañas, le otorga esa misma honrosa distinción en la rama de Teologia, para destacar no sólo el notable conocimiento de Dios y de los tratados teológicos que estudió en la Universidad Gregoriana y que poseía a fondo Monseñor Romero, sino sobre todo, la Maestría de Pastor en transmitir su experiencia de Dios al pueblo más necesitado, para alentarlo en la consecución de su liberación integral y por haber amado hasta el herọico sacrificio de sí, que constituye la esencia de la sabiduria cristiana.

Este acto tiene también para mi y para la Arquidiócesis de San Salvador, valor de signo. Una universidad católica o de inspiración cristiana tiene que favorecer el diálogo entre ciencia y fe y entre fe y cultura.

Esa tarea debe hacerse en armonía entre el teólogo que reflexiona, profundiza y expone en forma sistemática el dato revelado, según el método propio de la ciencia teológica, y el Magisterio Jerárquico que con la asistencia del Espíritu Santo custodia santamente el depósito de la fe.

Que este acto, pues, en que se conjuga: Universidad, teologia y Jerarquia, reafirme la vocación católica de la UCA y aliente a sus teólogos a seguir en armonia con el magisterio jerárquico, el diálogo, hoy más que nunca necesario, entre ciencia y fe y entre cultura y fe.

Con ese augurio, no me resta sino agradecer en nombre de la Arquidiocesis este solemne acto académico en honor del IV Arzobispo de San Salvador, Monseñor Oscar Arnulfo Romero. 